\title{
Atividade Reflexiva com Mulheres que Sofreram Violência Doméstica
}

\author{
Reflexive Activity With Women \\ Who Suffered Domestic Violence \\ Actividad Reflexiva con Mujeres \\ que Sufrieron Violencia Doméstica
}

Maria Eduarda Ramos

Universidade Federal de

Santa Catarina

Leandro Castro

Oltramari

Universidade

do Vale do Itajaí

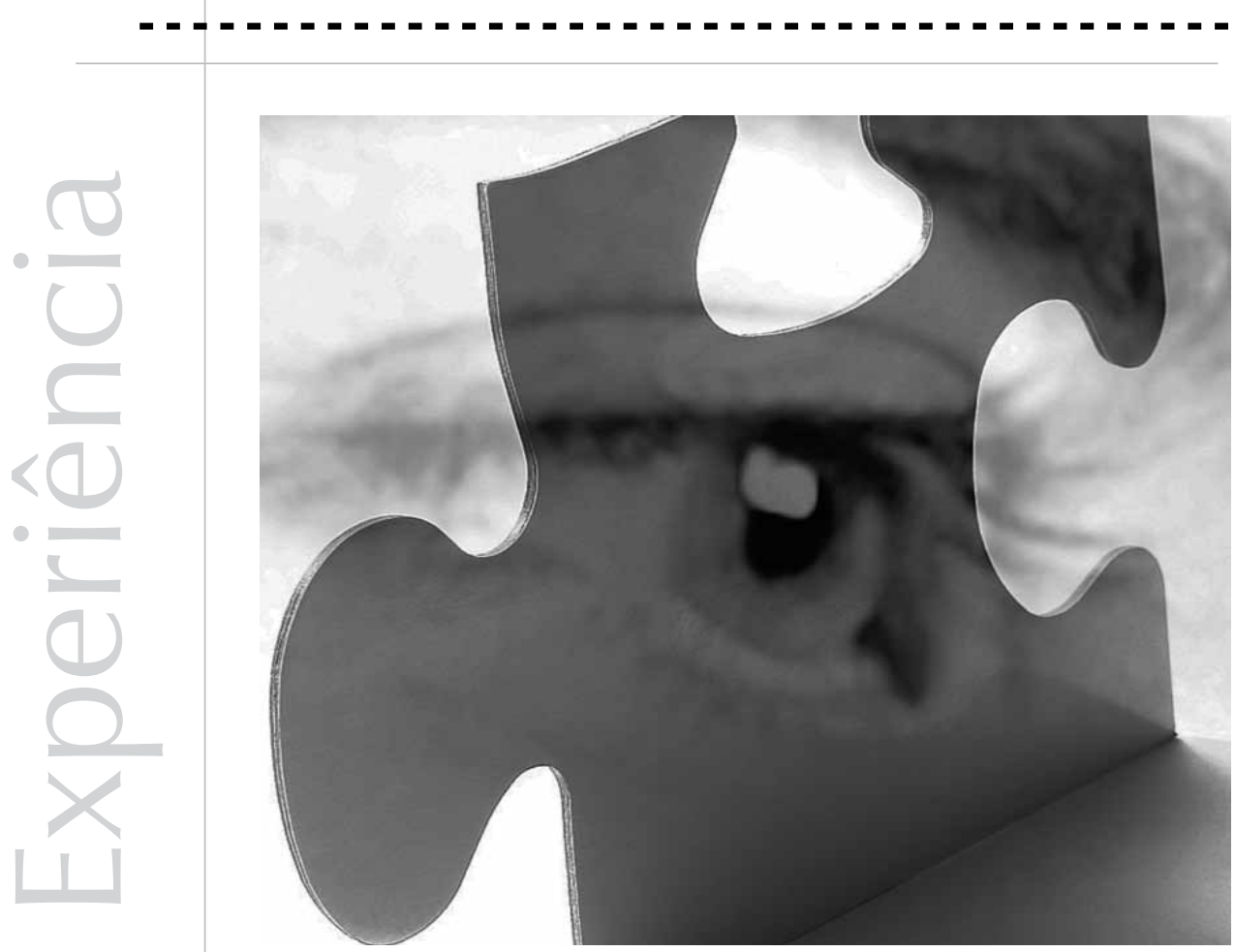


Resumo: Este trabalho está baseado em uma atividade reflexiva de grupo com mulheres que sofreram violência doméstica. Esse grupo teve como objetivos: promover discussões que propiciassem a reflexão das mulheres sobre novas formas de enfrentamento das situações de violência ou das consequências desta e formar uma rede social de apoio às mulheres e oportunizar vivências de interação entre as participantes para gerar aprendizagem, desenvolvendo mudanças na sua realidade social. Para isso, foram utilizadas reflexões de ensino-aprendizagem baseadas nas teorias de Paulo Freire, nas quais todos(as) ensinam e aprendem. $\mathrm{O}$ grupo proporcionou a aprendizagem de novas formas de agir e pensar por meio da interação entre suas participantes. As mudanças foram percebidas através dos relatos sobre a forma pela qual conseguiam buscar seus direitos de igualdade de gênero, ou ainda, como estavam agindo, não se submetendo às agressões físicas e psicológicas de seus companheiros, repensando suas atitudes em relação a eles. Identificou-se, por meio deste trabalho, que, quanto mais agentes multiplicadores se mobilizarem para fazer algo, mais se promove uma sociedade que reflita sobre os papéis estabelecidos para mulheres e homens, sobre a desigualdade de gênero, os direitos humanos e a violência doméstica.

Palavras-chave: Violência contra mulheres. Violência na família. Grupos de apoio. Ensino-aprendizagem.

Abstract: This paper is based on an activity that ocurred in a reflexive group activity with women who suffered domestic violence. This group had as objectives: the promotion of discussions which would favor reflection among these women about new ways of dealing with violent situations or its consequences and the creation of a support network for these women, providing them with an opportunity for social interaction among them, so there might be some learning and changing processes in their social realities. For that, teaching-learning reflections based on Paulo Freire's theories were useful, so that everyone involved in the debate group could teach and learn. The group provided these women an opportunity to act and think through interaction among the group members. These changes were noticed by the way they were now able to stand up and fight for their rights of gender equality, and the way they acted, differently from before, no longer submitting themselves to physical or psychological aggression inflicted by their partners and reviewing their own attitudes in their relationships. It was identified through this research that the more social agents stand up to do something about domestic violence, the more reflections about gender equality and papers stablisheds by society, domestic violence and human rights are promoted.

Keywords: Violence against women. Family violence. Support groups. Teaching-learning.

Resumen: Este trabajo está basado en una actividad reflexiva de grupo con mujeres que sufrieron violencia doméstica. Ese grupo tuvo como objetivos: promover discusiones que propiciasen la reflexión de las mujeres sobre nuevas formas de enfrentamiento de las situaciones de violencia o de las consecuencias de ésta y formar una red social de apoyo a las mujeres y tornar oportunas vivencias de interacción entre las participantes para generar aprendizaje, desarrollando mudanzas en la su realidad social. Para eso, fueron utilizadas reflexiones de enseñanza-aprendizaje basadas en las teorías de Paulo Freire, en las cuales todos(as) enseñan y aprenden. El grupo proporcionó el aprendizaje de nuevas formas de actuar y pensar por medio de la interacción entre sus participantes. Las mudanzas fueron percibidas a través de los relatos sobre la forma por la cual conseguían buscar sus derechos de igualdad de género, o inclusive, cómo estaban actuando, no sometiéndose a las agresiones físicas y psicológicas de sus compañeros, repensando sus actitudes en relación a ellos. Se identificó, por medio de este trabajo, que, cuanto más agentes multiplicadores se movilizaren para hacer algo, más se promueve una sociedad que refleje sobre los papeles establecidos para mujeres y hombres, sobre la desigualdad de género, los derechos humanos y la violencia doméstica.

Palabras clave: Violencia contra mujeres. Violencia doméstica. Grupo reflexivo. Enseñanza-aprendizaje.

A violência contra mulheres é considerada um dos pontos que merecem atenção urgente, já que, segundo Azerêdo (2007), há um crescente aumento no número dessa violência, que inclui várias formas, como violência física, psicológica, estupro, ameaças e desrespeito em relação aos direitos sexuais e reprodutivos, entre outros. Outras autoras (Suárez \& Bandeira, 1999) afirmam que não houve um aumento de casos, mas que a violência doméstica ganhou visibilidade ao ser desencadeada com a luta do movimento feminista contra essa prática. Esse tipo de violência se reforça com a discriminação contra mulheres (Azerêdo, 2007). Com isso, é possível destacar que estudos sobre o tema violência contra mulheres contribuem para o constante repensar dessas práticas violentas e do preconceito de gênero em nosso cotidiano. 
Levando em conta esse contexto, em 2006, entrou em vigor a Lei no 11.340/06, conhecida como Lei Maria da Penha (Brasil, 2006). Essa Lei tem como proposta criar mecanismos para coibir e prevenir a violência doméstica e familiar, e prevê campanhas e programas que promovam o enfrentamento da violência. Este trabalho irá relatar uma das muitas formas possíveis de atendimento às mulheres que sofreram violência, o que está previsto na Lei.

Abordar-se-á a atividade realizada em uma instituição de apoio a pessoas que sofreram algum tipo de crime ou de violência, que fornece amparo jurídico, social e psicológico para vítimas e familiares. Foram atendidas nessa instituição, no período de janeiro a outubro de 2007, 201 pessoas, sendo que $88,06 \%$ eram mulheres. Alguns dados que caracterizam os casos atendidos são: situações de violência doméstica (38,3\%), estupro $(3,48 \%)$ e assédio sexual $(0,50 \%)$, que somam $42,28 \%$ dos casos ${ }^{1}$.

Há uma procura significativa pelo serviço em decorrência da violência doméstica contra mulheres nessa instituição. Esse tipo de violência foi, em sua maioria, praticado pelo cônjuge. Isso é compreendido por algumas autoras como problemáticas que envolvem as discussões de gênero, em que o casal "cristaliza e reforça um círculo vicioso e perverso entre os gêneros" (Oliveira \& Vianna, 1993, p. 163). Gregori (1993) expõe que não se pode determinar uma forma geral de violência conjugal, e que há inúmeras motivações para que a relação violenta aconteça na relação conjugal, portanto, é necessário compreender o contexto em que a briga ocorre e o seu significado. Não há uma única causa ou explicação para a violência contra mulheres, principalmente quando se trata de violência conjugal, pois há mulheres que permanecem na relação de violência mesmo existindo questionamentos constantes sobre o que faz essas mulheres continuarem na relação que causa sofrimento (Grossi, 1998).
Para intervir com essa população, foram estabelecidos grupos reflexivos de gênero que vêm se mostrando uma alternativa para se trabalhar com homens e mulheres no enfrentamento da violência intrafamiliar e de gênero. Esse modelo de grupo reflexivo "constitui um espaço de inclusão dos sentimentos, da subjetividade e das relações em um sistema grupal de convivência e reflexão" (Acosta, 2004, p. 23). É um espaço de reflexão sobre o cotidiano de seus participantes. Não é um trabalho terapêutico, porém tem efeitos terapêuticos. O grupo permite a troca de vivências, situações, sentimentos e histórias semelhantes que serão compartilhadas com os demais membros. Nas conversas, são proporcionadas identificações e diferenciações que possibilitam a construção de alternativas para as situações de violência doméstica (Acosta, 2004).

Em 2006, foram iniciadas atividades reflexivas de grupo com mulheres em situação de violência doméstica. Esse grupo teve como objetivo promover discussões que propiciassem a reflexão das mulheres sobre novas formas de enfrentamento das situações de violência ou das consequências desta, e buscava também discutir a formação de uma rede social de apoio às mulheres vítimas de violência doméstica, além de oportunizar vivências de interação entre as participantes com a finalidade de aprendizagem, desenvolvendo mudanças na sua realidade social.

\section{Grupo reflexivo de mulheres que sofreram violência doméstica}

O trabalho partiu de uma perspectiva da Psicologia educacional, na qual se compreende que as mulheres participantes do grupo se comprometem com sua realidade quando se distanciam dela, para objetivá-la, observá-la e transformá-la (Freire, 1979). É necessário um afastamento do objeto para se ter um olhar crítico e para refletir sobre essa realidade. Quando a realidade se torna objetiva, faz com que os sujeitos possam 


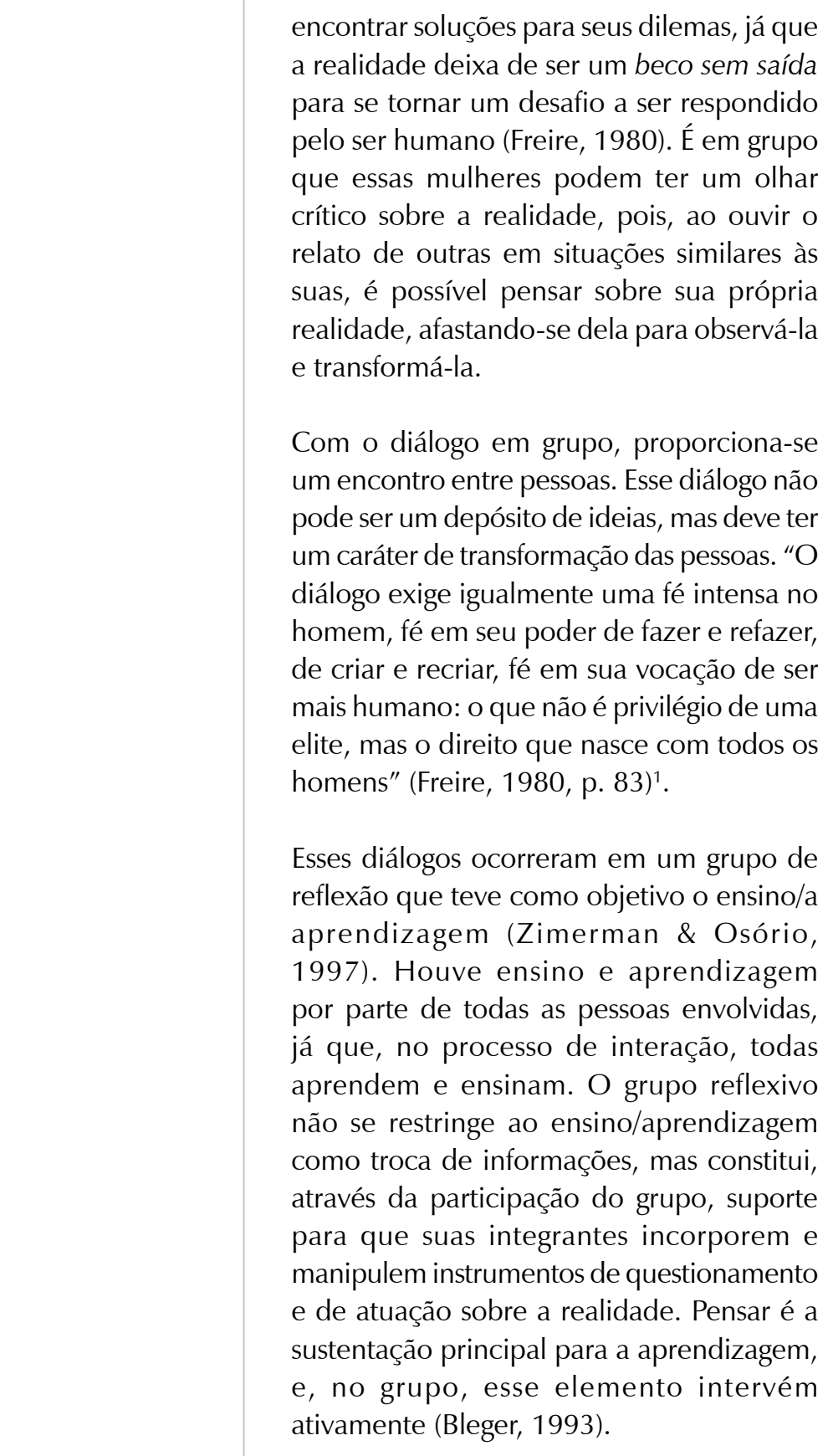

${ }^{1}$ A palavra homem é empregada pelo autor para designar ser humano. Os autores do presente artigo não concordam com a utilização do termo homem para substituir ser humano, mas mantiveram a citação devido à literalidade da citação.

No grupo de mulheres, cada participante ensina e aprende ao mesmo tempo. Isso se dá através das trocas de experiências, de discussões sobre as mulheres na sociedade, de exposição de sentimentos e de reflexão sobre as atividades de grupo, ou seja, pela homogeneidade e pela heterogeneidade das ideias de cada uma.

Mulheres em situação de violência doméstica Entende-se a violência doméstica como um fenômeno social grave que causa consequências físicas e psicológicas para seus envolvidos. É rotineiro, de longa duração, e envolve não só a violência física como também a emocional e a psicológica (Morgado, 2004). Esse tipo de violência ganhou visibilidade com as lutas dos movimentos feministas, que denunciavam as situações utilizando frases como Quem ama não mata. Estudiosas feministas elaboraram muitas perspectivas sobre a violência doméstica contra mulheres. Algumas delas compreendem que as mulheres eram vítimas das agressões dos homens, e outras ainda levavam em conta as relações de gênero e hierárquicas entre homens e mulheres.

Gregori (1993) propõe outra perspectiva para os casos de violência conjugal. Para ela, não existe uma dualidade entre algoz e vítima, ou seja, discorda da ideia de que o agressor seja ativo e a vítima, passiva. Segundo a autora, existe uma tendência em culpabilizar a diferenciação de gênero - em que a mulher é ensinada a ser subordinada para explicar a causa das relações violentas. No entanto, essas diferenciações de gênero ocorrem nas relações dos casais em geral, não caracterizando exclusivamente aqueles que vivenciam a violência doméstica. Ao construir a dualidade entre homem agressor e mulher vítima, a positividade é de denúncia e indignação. Entretanto, deixa-se desfocado o fato de haver uma parceria na relação conjugal, em que o casal utiliza a violência como forma de comunicação.
Nessa comunicação, o casal discute ou disputa com o objetivo de ver quem dará a palavra final. Assim, é feita uma cena, um jogo em torno dessa discussão. Cada um dirá algo que tentará fazer o outro se calar, e então, um acordo final se torna impossível. A cena terá fim em três hipóteses, segundo Barthes (1998): cansaço mútuo dos parceiros, chegada de uma terceira pessoa ou a substituição da réplica por agressão. É 
questionado se a agressão faz parte do jogo e da cena. Ao empregar o xingamento, há um desfecho do primeiro jogo e o início de outro. Nesse segundo momento, existirá uma vítima e um agressor. A vítima dará a última palavra do jogo de que foi parceira. Ser vítima é aderir a uma imagem de mulher, portanto, esse é um jogo perverso de feminilidade e masculinidade (Gregori, 1993).

A vítima constrói uma queixa. Essa narrativa colabora para incitar as condições de violência. A queixa consiste em narrar o $E u$ como vítima e inocente, e o Outro, como agressor e culpado. Essa situação tem por objetivo expor um sofrimento. Em grupos de mulheres que sofreram violência, facilmente surge a competição sobre quem foi mais violentada (Gregori, 1993).

No grupo reflexivo, foi utilizada a perspectiva de Gregori, em que as mulheres não são vítimas, mas participam de uma relação violenta. Foi utilizada essa perspectiva porque a proposta do grupo era que as mulheres refletissem sobre si mesmas, sobre suas atitudes e sobre as possibilidades de enfrentamento diante da situação de violência. Entende-se que, nesse contexto, a utilização dessa perspectiva foi pertinente, sem que se descartem demais reflexões teóricas sobre a violência contra mulheres.

\section{Encontros}

A partir de agora, serão relatados encontros do grupo de reflexão. Nos primeiros encontros, foram desenvolvidas atividades de apresentação, vínculo e ambientação. Elaborou-se um ambiente com almofadas, tapete e um painel em que estava escrito o nome do grupo - Grupo reflexivo de mulheres vítimas de violência -, entre outras informações, como o nome das coordenadoras. Esse ambiente foi montado em uma sala própria para o atendimento ao grupo. Tanto as questões de local dos encontros, horário, periodicidade, esclarecimentos sobre faltas, termo de compromisso, quem seriam e a quantidade de participantes, a finalidade do grupo e outras combinações, ou seja, o enquadre ${ }^{2}$, foi discutido no primeiro encontro.

No primeiro encontro, além das apresentações de cada integrante do grupo - participantes, coordenadoras (estagiárias de Psicologia) e psicóloga da instituição -, foi realizada uma atividade similar a um quebra-cabeça, que teve por objetivo apresentar a proposta de um grupo reflexivo. Foi acordado que cada participante desenharia ou escreveria a sua proposta em uma folha que se encaixava com as demais na forma de quebra-cabeça. As participantes desenharam nas folhas e deram seus significados, como, por exemplo, o desenho de dois corações que a participante disse serem o seu e o da filha. A filha foi apontada como motivo da separação, já que é do primeiro casamento, e o marido não a aceitava. Outras se desenhavam sentadas em posição de reflexão, ou desenhavam animais ou objetos que apreciam, outras ainda somente escreveram seu nome. Com essa atividade, foi possível refletir sobre a interação das participantes no grupo, cada uma com sua singularidade formando uma rede de apoio juntas e interagindo entre si. Essa interação se deu no grupo através de uma dinâmica na qual ao mesmo tempo em que as pessoas ensinavam, aprendiam umas com as outras (Bleger, 1993). A formação do vínculo entre as participantes do grupo foi importante para gerar confiança entre elas, assim, puderam dividir suas questões pessoais com as demais e puderam ser reconhecidas pelo grupo. Isso gerou um sentimento de pertencimento. Conforme o grupo se conhecia, o vínculo entre as participantes aumentava, tornando possível reconhecer-se na outra, com suas negações e suas fragilidades (Zimerman \& Osório, 1997), o que facilitou o auxílio mútuo entre elas.

Já no primeiro encontro, a maioria das mulheres trouxe suas histórias de violência. Uma delas, especificamente, relatou no início que não iria falar sobre si, porque não se 
Muitas vezes, as mulheres que sofrem violência não consideram esses atos como violência (Morgado, 2004). sentia segura. Entretanto, com as narrativas das outras, ela também resolveu falar daquilo que ela identificou como seu sofrimento (as agressões que sofria, entre outras questões). Algumas falas das mulheres ilustram essa primeira discussão do grupo: "Sinto falta dele, apesar de tudo. Quando ele era bom, ele era muito bom" (Dora); "Não sou capaz, não dou conta nem da casa e dos filhos, quanto mais de trabalhar fora" (Carla); "Quando você vê acontecendo violência com outras mulheres, você pensa que é um absurdo, mas quando é com você" (Cintia). O discurso queixoso pôde ser constatado a partir das falas das participantes do grupo.

O lugar representado pela queixa para essas mulheres também pôde ser representado no momento em que as coodenadoras, nos primeiros encontros, propuseram modificar o nome do grupo. Elas preferiram permanecer com o nome: Grupo reflexivo de mulheres vítimas de violência. Esse nome só foi questionado pelas participantes após muitos encontros e reflexões, despertando, assim, o desejo de modificá-lo para Grupo de mulheres ("A palavra mulheres já diz tudo. Já cabe ali sofrimento, alegria, força, coragem, tudo, - comentou uma das participantes).

Muitos dos encontros foram baseados nas trocas de queixas e relatos dessas mulheres. Os assuntos presentes nesses discursos foram: insatisfação com o companheiro, falta de confiança em si mesma, amar o companheiro mesmo na relação violenta, proteção e cuidado com o cônjuge, o lugar das mulheres como donas de casa, esposas e mães, traições do marido, alcoolismo e vícios do companheiro, incapacidade de sair dessa situação de violência e problemas com a sexualidade, entre outros. De maneira geral, os temas relatavam questões de gênero, não o posicionamento das mulheres como sujeitos na relação, e a desvalorização de si mesma. As mulheres afirmaram, em seus discursos, que o casamento era um projeto de vida a longo prazo que havia sido desestabilizado pelas condutas inadequadas do marido, como bebedeira, mulheres, boemia, práticas sexuais exageradas. Todo discurso para explicar o conflito conjugal culpabiliza os homens e suas fraquezas (Gregori, 1993).

Algumas falas como as descritas a seguir demonstraram suas queixas: "O pai deles fez eu matar (aborto) o irmãozinho deles, e meus filhos nem sabem disso" (Rosani); "Fui obrigada a denunciá-lo porque apanhei na frente de todos os vizinhos. Depois eles diziam que, se eu não fosse denunciar, eles iam" (Cintia); "Ele diz que eu não presto. Ele fica falando mal de mim para todos os amigos dele. Eu não mereço isso, porque sei cozinhar, limpar a casa, sou uma boa esposa" (Bruna); "Minha família me criou para ficar com o marido, não para separar" (Bruna); "Ele não me bateu, mas sofri violência psicológica, negligência com a família, não é violência? Claro que é" (Amanda).

Muitas vezes, as mulheres que sofrem violência não consideram esses atos como violência (Morgado, 2004). Essa percepção foi relatada em alguns casos, como, por exemplo, "Ele não me machuca como antes, agora só dá tapa, chute. Nada que me deixe marcada" (Carla); "Nunca sofri violência, quem foi violentada foi minha filha;... Ele me forçava a transar com ele, era horrível" (Rosani).

A queixa, como expõe Gregori, é presente no discurso dessas mulheres. No entanto, foi necessário ouvir os seus relatos queixosos para que o grupo interagisse a partir de suas falas. A discussão entre elas, sobre semelhanças e diferenças, conselhos e questionamentos, foi fundamental para a convivência entre as participantes. Ao ouvir os relatos, elas entraram em contato com suas realidades, observando-as com certo afastamento. Com esse olhar distanciado do objeto, foi possível desenvolver uma reflexão crítica sobre a realidade (Freire, 1979). Portanto, ouvir as queixas dessas mulheres e fazer com que se escutassem reciprocamente permitiu-lhes apreender novas formas de pensar e agir frente à violência que enfrentavam (Freire, 1979). 
A cada encontro, ao relatarem as queixas e seu papel de mulher-sujeito ou não em suas relações conjugais, familiares e profissionais, as demais participantes do grupo se mobilizavam e aconselhavam umas às outras, mesmo quando aquela que havia aconselhado desempenhava um papel igual ao da aconselhada, como, por exemplo, "Todas são guerreiras e são capazes de sair dessa situação" (Dora). Essa fala foi de uma das participantes para outra que estava em um momento de fragilidade. No entanto, a autora da frase, muitas vezes, demonstrou também seus momentos de fragilidade.

Com esse tipo de relação de mútuo apoio e ensino/aprendizagem, foi possível a reflexão das participantes do grupo. Exemplo: "Quando aquela mulher falou no grupo que ficou 40 anos casada e não mudou, eu fiquei pensando em mim, o que vai ser de mim" (Carla). Também houve, em determinados momentos, propostas de reação em que uma participante atribuía uma tarefa à colega de grupo. Por exemplo: "Esta semana você vai fazer uma tarefa, irá ser como uma parede de seu marido. Tudo que ele fizer, você vai fazer igual" (Marcia). Essas atividades eram propostas espontaneamente pelas participantes do grupo. As mulheres também traziam poesias, histórias, entre outras reflexões para o grupo. Podemos compreender que isso foi possível através do diálogo que lhes possibilitou refazer, recriar e criar outras formas de enfrentamento da violência (Freire, 1980). Ao conversarem com as outras participantes, criou-se um ambiente de diálogo e de reflexão, o que possibilita modificar a realidade de cada uma.

Foi utilizada, em alguns momentos, a técnica da troca de papéis e a dramatização, em que as participantes interpretavam situações que viveram. Nessa interpretação, elas representavam ora a si mesmas, ora seus companheiros, ou ainda membros do grupo encenavam situações da vida de uma outra participante, encenando como achavam que a colega deveria ter agido. Nessa atividade, foi possível mostrar às mulheres seu papel no relacionamento, seja quando não agiam ativamente e se submetiam às agressões dos companheiros, seja quando agiam como sujeitos, revidando e expondo suas opiniões no relacionamento e muitas vezes não se reconhecendo em tal papel. Essa técnica teve como objetivo a ruptura dos estereótipos ou de hábitos e a possibilidade de visualizar os conflitos de outras formas que não fosse apenas pela visão do sujeito (Osório, 2003).

Outra atividade que possibilitou a reflexão sobre gênero e violência foi a proposta de leitura de uma história em quadrinhos. Nessa história, uma mulher relatou a relação violenta com seu namorado e como saiu dessa relação. As coordenadoras entregaram trechos da história, e as mulheres leram e comentaram as semelhanças com suas próprias vidas. A partir disso, foram realizadas reflexões sobre o seu relacionamento com os companheiros ou ex-companheiros.

Também foram trazidas para o grupo cinco músicas - Cotidiano, Valsinha, Cara Estranho, Homens e Safado, cachorro, sem-vergonha. Essas músicas se referiam a temas como: homens e o que se esperava e se reprovava neles; o desejo por alguém mais atencioso, companheiro, que tenha respeito pela companheira; pessoas que não se posicionam como sujeitos na vida e o retrato do cotidiano de trabalho doméstico, presente em uma das músicas. Esses temas mobilizaram as mulheres para repensarem sobre as discussões de gênero. Uma das músicas que mais gerou reflexão, por exemplo, foi Cotidiano, que se refere a uma mulher que tem uma rotina doméstica de cuidados com a casa e o marido. A discussão no grupo foi em torno do papel dessa mulher. Algumas concordavam com o que era retratado na música, e outras discordaram. Então, a partir das divergências, as mulheres fizeram uma reflexão em que, para muitas delas, foi possível visualizar outras formas de viver diferentes da vida doméstica.

Através de quadrinhos e músicas, as mulheres puderam refletir sobre si mesmas e sobre seus relacionamentos. Tomaram consciência de 
sua realidade através de uma ação-reflexão, lendo os quadrinhos e ouvindo a música para uma aproximação crítica (Freire, 1980).

Em um dos encontros, uma das participantes relatou estar "largando a caneca de pedinte e se responsabilizando por sua vida e felicidade" (Glória). A partir dessa fala, as coordenadoras propuseram uma atividade: as mulheres escreveriam suas queixas em um papel (exemplos, "gostaria de meu marido me valorizasse", "queria que minha filha me desse atenção", entre outras). Depois deveriam jogar as queixas em uma caneca denominada: caneca do pedinte, ou seja, aquela caneca que se utiliza para pedir esmola aos outros. Em seguida, cada participante pegou aleatoriamente um papel de dentro da caneca, sem ser o seu papel. Elas leram para o grupo o que estava escrito e depois disseram se se identificavam ou não com o que leram, e qual conselho dariam para quem escreveu a queixa. Também foi questionado ao grupo quem mais se identificava ou não com o que foi lido. Essa dinâmica rompeu a fala queixosa das participantes, já que falavam da queixa de outra, e não diretamente de si mesmas. No final, todas devolviam os papéis para a caneca do pedinte, que foi jogada no lixo (simbolizando o abandono das queixas). As mulheres do grupo relataram que a dinâmica serviu para conhecerem que havia sentimentos semelhantes entre elas e o quanto se queixavam sem agir para mudar a situação.

Ao se colocarem no papel de vítimas e verbalizarem suas queixas, essas mulheres ficavam passivas diante de suas vidas. Quando foi proposto a elas que deixassem de se queixar e se responsabilizassem por si mesmas, através do simbolismo da caneca do pedinte, apesar da dificuldade, conseguiram realizar a tarefa. A maioria das mulheres expressava o sentimento de serem vítimas, e foi através da narrativa que isso foi percebido como um traço identificatório entre elas. Esse sentimento de ser vítima, por um lado, pode ser positivo, uma vez que faz as mulheres procurarem a delegacia e denunciarem a violência (Oliveira \& Vianna, 1993). Entretanto, diante da vida e da situação de violência, essas mulheres demonstraram não conseguirem se perceber como agentes atuantes na relação e capazes de se responsabilizar por si mesmas.

Alguns casais mantêm uma relação de violência de forma não reflexiva ou espontânea, e participam do jogo de acusações e xingamentos. Entretanto, é no corpo da mulher que haverá maiores danos, e é nela que o medo se instala, como é frequente ouvir nos relatos das participantes do grupo: "Peguei o ônibus com o olho roxo, o cobrador me olhava e eu morri de vergonha" (Carla). A mulher se torna vítima nessa situação, pois sofre os danos físicos e psicológicos, porém, de certa forma, é uma relação de violência, e, quando as mulheres se colocam como não sujeitos, passivas, fazem parte desse ciclo de violência (Gregori, 1993).

Foram realizados três encontros com histórias que davam possibilidade de reflexão sobre suas condições de agência diante da situação que vivenciavam, de se responsabilizarem por suas vidas, de lutarem pelos seus ideais e pelos seus direitos e de enfrentarem as suas dificuldades. Houve dois discursos presentes nas reflexões. Um deles era que "sou sempre engolida pela vida" (Carla); "Não consigo" (Márcia); "Estou vivendo tudo isso por castigo, eu mereço estar passando por isso" (Carla). E outro era: "eu estou enfrentando os desafios da separação, é difícil, mas eu vou conseguir" (Dora); "Enfrentei as situações complicadas de doenças, inclusive, e sei que vou superar" (Amanda). Então, as mulheres que se mostravam mais confiantes diante do futuro apoiavam as que estavam inseguras, sugerindo possibilidades de enfrentamento das situações, como, por exemplo, "arruma um emprego, eu vi que tem vaga numa loja, vou te passar" (Amanda). Esse é um exemplo do processo educativo que o grupo vivenciou, de ensino/aprendizagem e apoio mútuo entre as participantes. 
Os encontros relatados, da caneca do pedinte e das histórias, enfocaram as participantes do grupo como sujeitos responsáveis por suas vidas. Foi uma tentativa de sair do papel de mulher vítima e se posicionar diante das situações que viviam. As reflexões foram feitas sobre a sua realidade, o que propiciou um olhar diferente, reflexivo, crítico, para essa realidade (Freire, 1980).

\section{Algumas reflexões sobre o trabalho em grupo}

As mulheres do grupo demonstravam, no início do trabalho, que não se reconheciam como agentes ativas na relação, capazes de tomar suas decisões, buscar seus direitos e viver sem o companheiro ou com o companheiro e sem a violência. As mulheres relatavam o medo de enfrentar os problemas da vida, como uma relação conjugal violenta, a falta de emprego, os cuidados com a saúde, entre outros que caracterizavam o medo de se responsabilizarem por si mesmas.

No grupo de mulheres, foi possível perceber que as mulheres não são apenas vítimas passivas ou assujeitadas, mas, muitas vezes participam da relação de violência (Gregori, 1993). Portanto, fazer a queixa e colocar-se no papel de vítima passiva era frequente entre essas mulheres. Além disso, não se podem excluir as diferenças de gênero na sociedade. Essas mulheres relataram um modelo que thes foi designado, ou seja, o de esposa que se responsabiliza pela casa, pelo marido e pelos filhos e que serve a todos sem pensar em si. No grupo, umas com as outras, elas puderam refletir sobre esse papel, reconhecer-se como agentes na relação e na violência e perceber sua capacidade e as alternativas para a situação em que vivem. Os encontros foram realizados com a utilização de diálogos e de relatos das experiências, dinâmicas de apresentação e vinculação ao grupo, músicas, quadrinhos e textos, entre outros.

O grupo proporcionou às mulheres novas formas de agir e pensar. Essas mudanças foram percebidas através dos seus relatos sobre a forma como conseguiam buscar seus direitos de igualdade em relação aos homens ou como estavam agindo com seus companheiros sem submissão às agressões físicas e psicológicas, repensando suas atitudes em relação a eles.

Com o grupo de reflexão, também foi possível formar agentes multiplicadores de conscientização para a diminuição da violência. Essa rede de multiplicadores foi percebida quando as participantes disseram que recomendavam o grupo e discutiam com outras mulheres em situação de violência. Essa é uma luta contra a violência de gênero, e quanto mais agentes multiplicadores existirem, mais será possível pensar em uma sociedade que reflita sobre os papéis desiguais estabelecidos para mulheres e homens, sobre violência doméstica e sobre direitos humanos. Essas questões são importantes para que se fomentem estratégias de políticas públicas que almejem o enfrentamento da violência contra mulheres.

Esse campo de atuação mostrou uma possibilidade de trabalho para o psicólogo e para outros profissionais dentro das políticas públicas, já que, com a Lei Maria da Penha, são garantidos a essas mulheres e aos(às) autores(as) de violência espaços de reflexão sobre a situação que vivenciam. Não obstante, existe ainda muito a ser estudado, refletido e discutido sobre a violência contra mulheres, não só por parte da comunidade científica como também dos próprios sujeitos envolvidos em relações violentas. 


\section{Maria Eduarda Ramos*}

Mestrado no Programa de Pós-Graduação em Psicologia da Universidade Federal de Santa Catarina, Florianópolis, SC - Brasil. Atuação em Psicologia Social, com ênfase em violência contra mulheres, gênero, feminismo.

\section{Leandro Castro Oltramari}

Doutorado Interdisciplinar em Ciências Humanas pela Universidade Federal de Santa Catarina, Florianópolis, SC

- Brasil. Atuação em Psicologia Social, com ênfase em Processos Grupais e de Comunicação. Professor titular da

Universidade do Vale do Itajaí, Biguaçu, SC - Brasil.

E-mail: leandrooltramari@gmail.com

*Endereço para envio de correspondência:

Rua Ferreira Lima, 247, AP 801 Centro - Florianópolis, SC - Brasil CEP 88015-420.

E-mail: mariaeduarda_ramos@yahoo.com.br

Recebido 27/1/2009, 1a Reformulação 8/9/2009, Aprovado 30/9/2009.

\section{Referências}

Acosta, F. (2004). Conversas homem a homem: grupo reflexivo de gênero: metodologia. Rio de Janeiro: Instituto NOOS.

Azerêdo, S. (2007). Preconceito contra a mulher: diferença, poemas e corpos. São Paulo: Cortez.

Barthes, R. (1998). Fragmentos de um discurso amoroso. Rio de Janeiro: Francisco Alves.

Bleger, J. (1993). Temas de psicologia: entrevista e grupos. São Paulo: Martins Fontes.

Freire, P. (1979). Educação e mudança. Rio de Janeiro: Paz e Terra.

Freire, P. (1980). Conscientização: teoria e prática da libertação: uma introdução ao pensamento de Paulo Freire. São Paulo: Moraes.

Gregori, M. F. (1993). Cenas e queixas: um estudo sobre mulheres, relações violentas e a prática feminista. Rio de Janeiro: Paz e Terra.

Grossi, M. P. (1998). Rimando amor e dor: reflexões sobre a violência no vínculo afetivo-conjugal. In M. P. Grossi \& J. M. Pedro (Ed.), Masculino, feminino, plural: gênero na interdisciplinaridade (pp. 293-313). Florianópolis: Ed. Mulheres.
Brasil. (2006). Lei no 11.340 , de 7 de agosto de 2006. Cria mecanismos para coibir a violência doméstica e familiar contra a mulher. Recuperado em 10 de outubro de 2008, de http://www.planalto.gov.br/CCIVIL/_Ato2004-2006/2006/ Lei/L11340.htm

Morgado, R. (2004). Mulheres em situação de violência doméstica: limites e possibilidades de enfrentamento. In $\mathrm{H}$. Gonçalves \& E. Brandão (Ed.), Psicologia jurídica no Brasil (pp. 309-339). Rio de Janeiro: NAU.

Oliveira, E. M. de, \& Vianna, L. A. C. (1993). Violência conjugal na gravidez. Revista Estudos Feministas, 1(1), 162-165.

Osório, L. C. (2003). Psicologia grupal: uma nova disciplina para $o$ advento de uma era. Porto Alegre: Artmed.

Suárez, M., \& Bandeira, L. (Ed.). (1999). Violência, gênero e crime no Distrito Federal. Brasília, DF: Paralelo 15.

Testoni, R. J. F., \& Tonelli, M. J. F. (2006). Permanências e rupturas: sentidos de gênero em mulheres chefes de família. Psicologia e Sociedade, 18(1), 40-48.

Zimerman, D., \& Osório, L. C. (Ed.). (1997). Como trabalhamos com grupo. Porto Alegre: Artes Médicas. 